\title{
Electromagnetic and mechanical design aspects of a high-speed solid-rotor induction machine with no separate copper electric circuit in the megawatt range
}

\author{
Juha Pyrhönen · Janne Nerg • Jussi Sopanen •
}

Aki Mikkola • Tuomo Aho

Published online: 27 June 2009

(C) Springer-Verlag 2009

Erratum to: Electr Eng (2009) 91:35-49

DOI 10.1007/s00202-009-0114-1

Unfortunately the online published and printed versions of the article contain error in the order of the authors' names and the affiliation.

The correct order of the authors' names should be: Juha Pyrhönen, Janne Nerg, Jussi Sopanen, Aki Mikkola, and Tuomo Aho and their affiliations should read as

J. Pyrhönen · J. Nerg · A. Mikkola · T. Aho

Lappeenranta University of Technology,

Lappeenranta, Finland

\section{J. Sopanen}

Saimaa University of Applied Sciences,

Lappeenranta, Finland

The online version of the original article can be found under doi:10.1007/s00202-009-0114-1.

J. Pyrhönen · J. Nerg $(\bowtie) \cdot$ A. Mikkola $\cdot$ T. Aho

Lappeenranta University of Technology, Lappeenranta, Finland

e-mail: nerg@lut.fi

J. Sopanen

Saimaa University of Applied Sciences, Lappeenranta, Finland 